screw the male blade home, causing some laceration of the mucous membrane of the urethra. I also had to enlarge the meatus in order to withdraw the instrument. It caused him but little incon venience. He was ready for another sitting the second day. He had passed quite a number of pieces, and seemed very much encouraged. We had some five sittings, crushing a tremendous amount of stone, but each time experienced greater trouble in withdrawing the lithotrite, until I suggested completing the operation by lithotomy. He said he could not listen to that; as he was afraid that after cutting he would not be able to do horseback riding again, and that he would go to a friend's house in the city for a few days and see how he felt. That is the last I have seen of him. It is reported by his friend that he passed great quantities of débris, and that he was now fully recovered.

Case 196.-An Arab, about 60 years of age, a tall, lank, lean, gaunt-looking specimen of humanity, ill nourished, but possessing great nerve power and endurance. Some six years ago he presented himself complaining of pain in the bladder and difficulty in urination, but for some reason he disappeared, and did not show himself again until May 20 of this year. On again examining him I found he had a stone of large size. $\mathrm{He}$ confessed that he had been troubled with it for twenty years, and there was certainly proof enough over his abdomen that it had been there for some time. From the pubes to the ensiform cartilage there was not a spot as large as a silver dollar that had not been scarred by the red hot iron. He was informed that the stone was large, that its removal would be difficult; but he insisted on saying that it was not large, as he had measured it himself by passing his finger up the rectum. The same day he was examined he was present at an operation where a stone was removed measuring $9 \times 10$ centimeters; he said, "Mine is no larger than that." After trying the lithotrite and being unable to get it between the blades, I urged him to allow me to perform the suprapubic operation, but he would not listen to that; so on the following day, after making another ineffectual attempt to grasp and crush it, I cut down through the perineum, entering the bladder, and to my consternation found the organ full, a solid mass, immovable in any direction. My incision was as large as the parts would admit, expecting to meet with a large stone, but not a boulder. I took the large forceps applying it in different ways, hoping I might be able to move it, but to no purpose. I again tried the lithotrite, but the blades would not come near each other. So using the forceps as a fulcrum to press the stone up over the pubes, I cut down in the median line. Coming on the bladder I found it greatly thickened, resembling a muscle rather than the bladder. An incision fully three inches long had to be made before it could be extracted. Much of it was crumbled off in the effort to withdraw it, both above and below, but I succeeded in removing a solid mass weighing 80 drachms, measuring 9.5 by 7.5 inches. Fully 20 drachms of it was thus lost, so that we had the stone lying in the bladder, before touching it, weighing $121 \%$ ounces. The upper wound was closed in the usual way, leaving the lower to do the draining, which to my mind, was what saved him, he being in the balance for a day or two. He began to show signs of gaining, and made a fairly good recovery, leaving the Hospital March 22 with only a small opening in the lower wound, which he had begged of me for a number of days to sew up as I had done the wound above.

Case 201.-June 19,1897, a child three years of age was brought, complaining of pain in passing water; he was examined and found to have stone. He was at once operated on, and being anxious to remove the stone without introducing my finger, I entered the bladder all right, grasping the stone, which went to pieces under the forceps, I removed everything I could find with the instrument and washed out the bladder with great care, hoping, yet doubting, that all had been brought away. The child was making a fair recovery, yet the old symptoms were as prominent as ever, so in July he was again brought and examined,and there was stone still remaining. I enlarged the former wound, making it large enough this time to introduce my finger. I found the bladder in the form of an hour glass, with the stone in the upper half. Expanding it with an injection of water, I removed about twice as much as I did the first time, my finger being within the bladder. I could find nothing more, yet he is not free from the old symptoms. It is a nice operation, if the stone can be extracted whole, not to introduce the finger, but when the stone is crushed in the extraction, nothing can give the positive evidence that the bladder is free from all debris but the introduction of the finger.

Case 202.-Our misfortunes, or unfortunate cases, do not look as well in print as the more fortunate and brilliant ones do; but it is through the misfortunes of one that others learn to avoid them, and for that reason it is our duty to give them publicity with the same candor we do our more successful cases. For that reason I will close with two of what I call unfortunate cases. This last case was operated on yesterday, the sacond of the kind in 202 cases of calculus it has been my fortune--and some of my patients' misfortune-to operate on. A child of three or four years of age, well nourished and in fine health, was brought to the hospital some five or six days ago. The father, who was with him, says that for nearly a year he was troubled by spells of having pain in passing water. I examined him and at once got the click of the stone. Yesterday he came prepared for the operation. The father said that since he was examined he had been free from pain in passing water. On introducing the staff I again got the former click, and making the wound large enough to introduce my finger, imagine my surprise and utter chagrin on exploring the length and bread th of the bladder not to find a stone in it! The case is doing well, but what was it I mistook for a stone?

In looking back through my records I find Case No. 72, aged 3 years, Turk, a very delicate child. In sounding no audible click was heard, and for that reason was removed from the operating table. The symptoms continued the same. The parents insisted on my trying again, which I did, with the same result. The sound seemed to come in contact with something, but getting no clear sound I refused to operate. The child suffered so much from the pressure of water that the father insisted on my operating; I consented, giving it as my opinion that it was unwise to do so. On entering the bladder, no stone could be found! Inflammation set in, carrying off the ittle fellow in twenty-four hours.

All these, in fact all my operations, are done without any assistance, except as my servants help.

July 8, 1897 .

\section{THE TREATMENT OF HEMORRHOIDS BY THE INJECTION METHOD.}

Presented to the Section on Surgery and Anatomy, at the Forty-eighth Annual Meeting of the American Medical Association, held at Philadelphia, Pa., June 1-4. 1897.

BY LEWIS H. ADLER, JR., M.D.

Professor of Diseases of the Rectum, Philadelphia Polyclinic and College for Graduates in Medicine; Surgeon to the Charit Hospital, and to the Out-patient Department of the Episcopal Hospital Dector the Professor of Anatomy, Medical Department University of Pent
PHILADELPHIA, PA.

I am sure that my experience is by no means unique, in that the majority of patients with hemorrhoidal troubles come to me greatly prejudiced against any operative procedure involving the employment of general anesthesia, and especially the use of the knife. These objections have been raised not only by the laity, but also by physicians who have been similarly affected. Such an argument should not and would not prove a factor in altering the character of advice to be given to a patient were I satisfied that only one plan of treatment could effect a cure; but where a choice of several methods exists for effecting the same or similar results it is not only our duty but a necessity for us to respect the patient's wishes.

In a number of instances, sufficient to convince me of the efficacy of the method and to enable me to place my opinion on record, I have treated internal hemorrhoids (in selected cases only) by the injection of carbolic acid. The results obtained in every instance have been entirely satisfactory to patient and myself.

I am thoroughly acquainted with the unsatisfactory experience and the unfavorable opinions expressed regarding this treatment by such authorities as Kelsey of New York, Mathews of Louisville, Ky., Allingham of London, and others of equal eminence, and I am, furthermore, free to confess that for a long time the weight of this evidence deterred me from giving the method a trial. On the other hand, I have diligently perused the literature, past and present, dealing with the other phase of the question, and after reading the excellent treatise on "Hemorrhoids and other Non- 
malignant Diseases of the Rectum," by W. P. Agnew, M.D. of San Francisco, I determined to test the merit of the treatment.

External hemorrhoids.-Agnew (op. cit., p. 18) admits that the quickest, neatest, least painful and most desirable way of disposing of any form of external hemorrhoid, cutaneous tag or like redundant tissue is by excision, but employs the carbolic acid injection in those cases in which the patient is averse to being treated by any plan involving the use of the knife or scissors. He claims that this method effects a cure, to which such persons will readily submit, although informed that a longer time is required for the complete eradication of a tumor thus treated and that more pain and inconvenience may be experienced from the effects of the operation than would result from that by excision.

Personally I have had no experience with this method of treating external hemorrhoids, preferring and always advising in operative cases the excision of such tumors.

According to the same authority (op. cit., pp. 22, 23 and 24 ) and as the result of his observations the objections to the treatment of external hemorrhoids by carbolic acid injection pertain solely to the length of time required for the removal of the tumor, a period of three or four days, and the pain following the injection, which is not intense, but is at times more or less annoying; usually beginning within one or two hours after the operation and continuing for twelve or fourteen. Agnew advises against the employment of this method in the treatment of external hemorrhoids when inflamed and in a highly sensitive state. He especially notes the care that should be taken when operating on these tumors by injection to see that quite a considerable portion of the cutaneous surface, especially at the summit of the pile is affected by the solution applied just beneath the skin, otherwise the skin will become inflamed, in order to let out the interior coagulum, which he has often seen come out in three days, without suppuration or'showing the appearance of much moisture and in one unbroken cystic-looking mass. The operation is to be performed with a view of cauterizing all the tissue to be removed, which can be governed only by the dictates of judgment and as a result of experience.

Internal hemorrhoids. - It is to the treatment of internal hemorrhoids by the injection of carbolic acid that I wish especially to invite your attention in the hope of eliciting a free discussion as to its merits or demerits based upon the actual experiences of those who have given the method a fair trial.

Formula.-The formula which I use is the one advocated by Agnew, and the method of its preparation is best detailed by a verbatim description as given in Dr. Agnew's work on diseases of the rectum (op. cit., pp. 3̄ and 36 ):

"The solution of carbolic acid found to be uniformly successful in the treatment of hemorrhoids is prepared by first making a solution of the acetate of lead and borax in glycerin in the proportion of two drams each of the chemically pure salts to one ounce of Price's glycerin:

\section{R Plumbi acetat.}

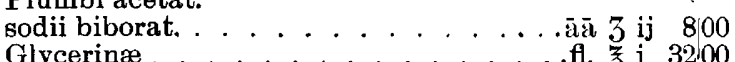

"Mix in a graduate, pour into a two-ounce vial, and let it stand for twenty-four hours. The solution of the salts is hastened by placing the vial in a warm water bath and allowing it to remain there for fifteen or twenty minutes. The glycerin can be handled to a better advantage and its measurements more accurately made and retained by warming it as well as the graduate before it has been poured into the graduate and the chemicals have been added.

"Select Calvert's No. 1 crystallized carbolic acid and pour a sufficient quantity, liquefied by warmth, into a two-ounce graduate to measure one ounce and add two drams of distilled water. To this add enough of the glycerid of lead and borax previously made to make the combination measure exactly two ounces.

R Acid carbolic (crys.) . . . . . . . . ₹ 3 j 3200

Aquæ destillat Sodii biborat et plumbi acetat et glycerin fl. 3 ij 800

Sodii biborat. et plumbi acetat. et glycerin.
Misce et sig. Solution for hemorrhoids.

"The object of the formula is to lessen the syruplike consistency of the preparation. Should equal parts of crystallized carbolic acid and the glycerid of lead and borax be combined, the solution will be found rather too heavy for convenience. It will not flow through the hemorrhoidal needle as freely nor take hold of the tissues when injected as quickly as does a solution containing a small proportion of water. Be particular in the weights and measurements and the purity of the ingredients entering into this preparation, as anything unnecessarily irritating should be scrupulous]y avoided. I have tried synthetic carbolic acid and found the odor of tar to be decidedly stronger, and believe it to be much more acrid and irritating than the commoner preparations; neither can I see that anything is gained in using vegetable glycerin.

"Some make no allowance in attempting to give the formula, for the increase in bulk of the glycerin occa. sioned by the addition of the one-half ounce of solids, and direct that the ounce of carbolic acid be added to the full amount of the glycerid of lead and borax when made. By this inadvertence not much over a 35 per cent. solution of carbolic acid is obtained. After trying the acid in varying strengths and watching its effects, I have concluded that not less than a 50 per cent. solution should be used. The addition to the solution of the acetate of lead is designed to restrict the action, and that of the borax to lessen the irritative properties of the acid. The acetate of lead not only keeps within limit the distribution of the acid at the time the solution is forced out of the hypodermic syringe, but of itself combines with a certain portion of the albumin of the blood and other tissues, forming the albuminate of lead. If I were to make a change in the formula it would be toward an increase rather than a diminution of the quantity of acid."

Preparatory treatment.-This includes a careful study of the patient's physical condition. I would advise against the employment of the injection treatment in cases predisposed to phthisis or already affected by this disease, and in diabetes or in chronic diseases of the liver, heart or kidneys.

During an acute inflammatory attack of hemorrhoids is not a favorable time to operate, on account of the engorged condition of the rectal vessels, and the irritability of the mucous membrane of the bowel. Such conditions should be relieved by local medica. tion and by remedies directed toward regulating the bowels and increasing the activity of the liver.

Operation.-At the time of operation the hemorrhoids are exposed by inducing the patient to have a stool or to sit over hot water. 
It is advisable to smear vaselin over the mucocutaneous surfaces prior to operating, as advised by Agnew (op. cit., p. 34), in order to prevent the solution used for the injection coming in contact with the parts.

The patient should be placed in Sims' position and the hemorrhoid being sufficiently well exposed, it is be punctured at its most accessible point, preferably about midway between its base and apex, and the point of the needle passed to about the center of the growth. Care must be exercised that the needle's point is inserted beyond the proximal end of its opening, as otherwise the preparation will be injected on the outside of the tumor. In a large growth eight or ten punctures may be found necessary.

The injection is to be inserted slowly, several drops at first, then drop by drop, watching the action of the solution as shown by the change of color that creeps over the surface of the pile. This change of color, Agnew states, is quite marked with hemorrhoids of a delicate coloring, less so with those possessed of more fibrous coats. The needle should be held in position for a short time, and if the quantity injected appears to be less than needed, more of the solution should be used. Agnew states that the solution takes effect slowly by virtue of its astringency and syrup-like consistency, and no doubt extends some farther than is always apparent at the time of operating. If the hemorrhoid be large and its cavities filled with blood exhibiting strong arterial pressure, more time will be occupied in performing the operation than is generally supposed, as many as twenty or thirty minutes occasionally being required. The time is taken up in such cases, by holding the needle in place until assured that sufficient of the solution has been used to effect the desired result. If the part feels doughy or springs up under the finger like an elastic ball when pressed, or blood flows freely through the place of puncture after the needle has been withdrawn, either enough time has not been allowed for the preparation to take effect or a sufficient quantity has not been injected.

After the entire cavity of the tumor has been thoroughly reached by the injection, and in a large tumor, a few drops have been deposited on the surface of the pile, so as to be sure of thoroughly cauterizing the more dense tissue of the integument, which Agnew states might otherwise inflame and create unnecessary pain and suffering, the hemorrhoid is to be thoroughly dried and covered with carbolized vaselin and returned within the bowel. Several tumors may be treated in this manner at one operation and I have seen no bad results ensue, although I have used several drams of the solution in a single treatment. No speculum is required, as a rule, in this method of treating hemorrhoids.

The needle required for the hypodermic syringe employed in giving these injections should have a little larger bore than the needle employed for ordinary hypodermic use, so as to permit the fluid to flow through readily, which the smaller needle prevents owing to the consistency of the injection fluid.

After-effects and treatment following operation.In some cases pain is experienced several hours after the operation, but is usually controlled by suppositories of the aqueous extract of opium, $\frac{1}{4}$ grain, and extract of belladonna, $\frac{1}{8}$ grain, used pro re nata. Difficulty in urination may occur and is usually relieved by a hot-water bag applied above the pubes, or by a sitz bath. Catheterization is seldom required. desire to have the bowels move can be allayed by the use of the suppositories and by hot water compresses applied to the anus.

I do not endeavor to confine the bowels for any definite period after this operation; usually the patient's fear of having a movement effectually restrains such a desire, and on the third day $I$ am in the habit of ordering fractional doses of calomel and soda, followed by a saline. Just preceding the time the bowels act I order a rectal injection of 8 ounces of carbolized oil ( 2 per cent. carbolic acid) or an injec. tion of slippery-elm tea or of borax water (a dessert. spoonful to the pint of water). A peculier odor sometimes noted when the coagulum is being thrown off, should not be interpreted as indicating suppuration.

Agnew states that to effect a safe, speedy and radical cure of a case of hemorrhoids, it is desirable to get rid of the tumor bodily, not by shrinkage or contraction, leaving a hard or indurated prominence subject to resuscitation and a return of the old malady, nor by inflammatory destruction, but by a separation of the spongy and vascular growth from the normal tissue of the body, the same as if it were dissected from its remotest attachments. This is obtained by putting a sufficient quantity of the preparation recommended just where it is required, and such results will invariably follow. $\mathrm{My}$ experience with the treatment thus far leads me to endorse most heartily Dr. Agnew's strong commendation of the method which he has so successfully employed for a long time. Personally, I can not speak authoritatively regarding the permanency of the cure effected by the carbolic acid injection in hemorrhoids, for I have not had an opportunity of observing cases treated by this method for a longer period than two years, but from my observations I am inclined to believe that it is a radical procedure.

Regarding the dangerous results following this treatment-of carbolic acid poisoning, embolism, sloughing and ulceration, or their sequelæ, abscesses or fistulæ, I have not witnessed any such results and am loath to believe that they do occur if the operation be performed carefully and skilfully and with a proper observance of aseptic principles.

1610 Arch Street.

Discugsion,

Dr. Brown of Indian Territory-I have operated on more than one hundred cases. Upon injecting carbolic acid I found the pain was increased, but when we used the chemically pure acid the pain was mitigated more than by any other. We also found that in this way there was no pain after the first few seconds, unless we happened to get the acid around the out. side. We have much less chance of its being absorbed. By injecting one hemorrhoid the whole mass will disappear, and one application is usually sufficient. I do not know exactly from what cause these results ensue, but the disappearance of the whole amount of hemorrhoids showed that the acid had been absorbed.

Salicylate of Methyl in Rheumatic Arthropathy.-The benefits of local applications of salicylate of methyl in arthralgia accompanying infective disease have recently been proclaimed, and a similarly beneficial effect has been observed in the arthropathy of subacute or chronic rheumatism after about 3 grams have been applied to the articulation. The secret of success is to enclose the joint afterward hermetically. For this purpose it is laid on a piece of rubber tissue, the salicylate of methyl rubbed in and the rubber tissue drawn up tight around it, enclosing the whole hand or foot as the case may be. Cotton may or may not be used inside.-Presse Médicale, July 28. 